\title{
Cattle-grazing in oil palm plantations sustainably controls understory vegetation
}

\begin{abstract}
Oil palm agricultural practices need to be substantially changed in order to meet the global demand for more ethical and sustainable farming. Livestock integration is an innovative method to control understory vegetation in oil palm plantations, while reducing the need for chemical herbicides, as well as providing additional food security, ecosystem services, and habitat heterogeneity. Understory vegetation is important for faunal biodiversity in oil palm plantations, however it is often decimated by the over usage of herbicides. To determine how cattle-grazing affected the growth of understory vegetation, we collected data from 45 plantations, in Peninsular Malaysia, including those integrated with cattle and without them. Our results revealed that the plantations integrated with cattle had on average $20 \%$ more undergrowth coverage, but no difference in undergrowth height, therefore, maintaining undergrowth at an acceptable height for harvesters to access oil palms. We recommend cattlegrazing as a method for oil palm stakeholders to maintain manageable undergrowth and align with sustainable palm oil certification policy by reducing their use of chemical herbicides. To promote cattle-oil palm integration, specific policies are needed to strengthen financial and technical support.
\end{abstract}

Keyword: Agricultural practice; Biodiversity; Ecosystem services; Grazing; Herbicides; Livestock 